\title{
NOTAS METODOLÓGICAS PARA A ANÁLISE DE DEBATES JURÍDICOS DURANTE A DITADURA
}

\author{
CARlos EduARdo SoARES DE FREITAS ${ }^{1}$
}

RESUMO: O estudo das relações dos direitos trabalhistas sob a ditadura civilmilitar brasileira deve articular ao menos três dimensões: os conflitos entre trabalho e capital e entre trabalhadores e o governo militar; o apoio empresarial à ditadura; e a cultura jurídica da época, entendendo-se como tal a produção intelectual no direito do trabalho. O objetivo deste artigo é traçar essa articulação a partir da investigação documental histórica e de entrevistas com ativistas sindicais da época. Para a pesquisa, adotou-se os seguintes parâmetros: o estudo da repressão oficial sobre os sindicatos baianos dos petroleiros e dos bancários; o exame do apoio empresarial à ditadura; a análise jurídica e judicial de normas propostas pelos governos militares e que desestruturaram a regulação do trabalho, em especial o FGTS, a partir dos posicionamentos de dois intelectuais: Orlando Gomes e José Martins Catharino. A pesquisa tende a contribuir no aprofundamento de reflexões acerca da relação entre direitos trabalhistas e democracia, em vista do estudo sobre os efeitos nas relações de trabalho de um contexto político de tipo autoritário, como a ditadura civil-militar e o que se configura contemporaneamente no Brasil, marcado pela radicalização do modelo neoliberal e precarização das relações laborais. Estudos preliminares permitem concluir que a repressão na ditadura aos movimentos dos trabalhadores foi acompanhada por condutas agressivas a opositores ao regime também na Faculdade de Direito da Bahia, onde eram professores Gomes e Catharino, e por posturas tímidas do judiciário em debates sobre garantias e direitos trabalhistas.

PalavRAS-CHAVE: Ditadura civil-militar; Direitos trabalhistas; Cultura jurídica; Bahia.

Professor Titular da Universidade do Estado da Bahia (Brasil). CV: http://lattes.cnpq.br/2215561308867534. Contato: carlosefreitas3@gmail.com. 
ABSTRACT: The study of labor rights relations under the Brazilian civil-military dictatorship must articulate at least three dimensions: conflicts between work and capital and between workers and the military government; business support for the dictatorship; and the legal culture of the time, understanding intellectual production in labor law as such. The purpose or this article is to trace this articulation form historical documentary research and interviews with union activists of the time. For the research, the following parameters were adopted: the study of the official repression on the Bahian oil and bank unions; the examination of business support for the dictatorship; the legal and judicial analysis of rules proposed by the military governments and which have disrupted labor regulation, especially the FGTS, based on the positions of two intellectuals: Orlando Gomes and José Martins Catharino. The research tends to contribute to the deepening of reflections on the relationship between labor rights and democracy, in view of the study on the effects on labor relations of an authoritarian political context, such as the civil-military dictatorship and what is configured at the same time. Brazil, marked by the radicalization of the neoliberal model and precarious industrial relations. Preliminary studies allow us to conclude that the repression in the dictatorship of the workers' movements was accompanied by aggressive conduct towards opponents of the regime also at the Bahia Faculty of Law, where professors were Gomes and Catharino, and by timid attitudes of the judiciary in debates about guarantees and labor rights.

Keywords: Civil-military dictatorship; Labor rights; Legal culture; Bahia.

\section{INTRODUÇÃO}

As notas que seguem representam resultados parciais de pesquisa em andamento cuja reflexão se concentra nos efeitos da ditadura civil-militar brasileira nas relações de trabalho e na regulamentação do Direito do Trabalho. O estudo se debruça sobre as categorias dos bancários e petroleiros na Bahia. As questões metodológicas e sobre as fontes são aqui objetos de análises fundamentais para a investigação.

\section{DESENVOLVIMENTO}

O artigo se propõe a examinar seis conjuntos de documentos, de diferentes fontes e registros, para melhor compreensão do cenário institucional do período, de modo a abranger: 1 . como juízes e judiciário lidaram com a política durante a ditadura (documento dos encontros dos juízes); 2. como o Ministério do Trabalho e Previdência Social entendia o momento político (Relatório ministerial em 1968); 3. como se conduziram os juslaboralistas aqui escolhidos no âmbito da Faculdade de Direito, onde eram professores (Relatório da Comissão de Memória e Verdade 
Eduardo Collier Filho da Faculdade de Direito da UFBA); 4. como a repressão da ditadura cuidou de avaliar, fiscalizar e acompanhar as condutas dos dois juristas (documentos do Arquivo Nacional); 5. como o movimento sindical tentou participar e interferir no debate em torno do FGTS (Parecer solicitado pela CONTEC); e 6. como o governo federal lidava com a resistência sindical (procedimentos de acompanhamento de eleição sindical).

O objetivo é traçar a articulação entre documentos e a análise sobre a regulamentação do Direito do Trabalho em diferentes dimensões: os conflitos entre trabalho e capital e entre trabalhadores e o governo militar, na luta pela garantia de direitos individuais e coletivos; o apoio empresarial à ditadura; e a cultura jurídica da época, por meio do exame da produção dos dois principais pensadores baianos do Direito do Trabalho. O limite temporal é dos primeiros anos da ditadura. $\mathrm{O}$ método utilizado combina a investigação documental histórica e falas de ativistas sindicais da época. Espera-se contribuir para o aprofundamento de reflexões acerca da relação entre direitos trabalhistas e democracia, em vista do estudo sobre os efeitos nas relações de trabalho de um contexto político de tipo autoritário, como a ditadura civil-militar e o que se configura contemporaneamente no Brasil, marcado pela radicalização do modelo neoliberal e aprofundamento da precarização das relações laborais.

\section{NOTA 1: ESCOLHAS}

Estas anotações se propõem a expor desafios metodológicos acerca de pesquisa sobre debates jurídicos em um contexto histórico marcado pelo despotismo político. Os debates jurídicos compõem parte do objeto da pesquisa. Sua justificativa é compreender a influência intelectual de pensadores do Direito na comunidade jurídica em espaço e tempo bem definidos: a Bahia na época da ditadura. Para isso, duas escolhas foram feitas. Primeiro, o acompanhamento dos dois juristas do Direito do Trabalho mais destacados e respeitados na época (mais precisamente, nos anos 1960 e 1970): Orlando Gomes e José Martins Catharino, ambos advogados, professores universitários, autores de obras marcantes no período e respeitados na comunidade jurídica.

A segunda opção delimita os temas referenciais para a análise, cujos assuntos: (i) envolviam propostas encaminhadas pelo governo autoritário ao parlamento; e (ii) as reflexões se relacionavam diretamente ao papel político da representação sindical.

De início, duas obras são analisadas enquanto documentos (REGINATO, 2017): Curso de Direito do Trabalho, de Orlando Gomes e Elson Gottschalk, na 3 $3^{\text {a }}$ edição, de 1968, e Temas de Direito do Trabalho, de José Martins Catharino, na 1a edição, de 1971. Foram examinados dois temas muito caros para a sociedade: o Fundo de Garantia por Tempo de Serviço (FGTS) e a política salarial, havendo mais atenção ao FGTS. 


\section{NOTA 2: CUIDADOS. A SEDUÇÃO PELA ANÁLISE TÉCNICA}

Os debates sobre temas do Direito do Trabalho ocorridos nos primeiros anos da ditadura devem ser estudados considerando o contexto político, sob pena da preocupação tecnicista do objeto discutido tomar toda a atenção e com o risco do exame se tornar acrítico e sem sentido histórico.

Considerando as diferenças entre descrição e análise, que tenham como origem um texto normativo, creio ser possível identificar aí ao menos duas táticas de investigação: uma ocupada em descrever, que se crê técnica em relação à norma e com viés de pouca ou nenhuma criticidade, e a outra preocupada com a análise do conteúdo e o contexto. A primeira se revela quando a escolha do pesquisador se limita a debates e artigos sobre como foram as atualizações salariais, as expressões adotadas ("correções", "reposições"), ou as regras para a liberação do FGTS, e que a partir daí, voltaram-se para problemas operacionais que eventualmente dificultaram condutas pragmáticas do empregador ou do empregado em cálculos ou na codificação para liberação da conta vinculada. Nestes casos, o estudioso acompanhará as preocupações dos juristas da época quanto aos detalhes da atualização salarial ou do FGTS. Com isso, poderá construir comparações provavelmente anacrônicas entre o que se discutiu no passado e o que ocorre atualmente, e fazer outras tantas reflexões e capturar algumas curiosidades dos debates jurídicos. Enfim, haveria aí uma opção exclusiva pela discussão técnica, entendendo-se como tal um suposto exame objetivo sobre o que dispuseram as normas e o que deveriam fazer empregadores e empregados, dadas as novas regras.

De outro lado, ir além dessa limitação descritiva exigirá do estudioso um esforço maior, como se fosse a contrapelo ${ }^{2}$, pois terá pela frente algumas tarefas complicadas: ampliar a sua visão para além do mero escopo do regramento, dirigirse ao seu sentido e tentar formular o máximo de questões sobre os debates, os debatedores, os ambientes produtores de debates e a própria época. A sedução pela análise "histórica" limitada à técnica pode se dar no apelo ao menor esforço do pesquisador: afinal, se aquela análise descritiva com ares históricos - pois o estudioso se debruçou sobre discussões pretéritas - já seria satisfatória para uma plateia minimamente curiosa nos tempos atuais, o que poderia ser mais analisado do que descrito?

O caso do FGTS pode fornecer algumas pistas para um estudo analítico dos debates durante tempos sombrios. O FGTS foi lançado pelo ditador Castello Branco em discurso na Assembleia Legislativa do Estado de Minas Gerais em 1966. Naquele momento, o militar defendeu uma série de reformas para o país: administrativa, previdenciária, trabalhista e tributária (FERRANTE, 1978). Este fato pode provocar um primeiro impacto àqueles que consideram novos e atuais os temas dessas reformas, retomadas no governo do ex-presidente Fernando Henrique Cardoso, anos após a ditadura. O FGTS se tornou uma opção ao

${ }^{2}$ Com referência à visão de cultura de Walter Benjamim. 
trabalhador, que poderia, caso não o quisesse, manter o regime da estabilidade decenal previsto no artigo 492 da Consolidação das Leis do Trabalho (CLT). Era, portanto, um direito de opção do trabalhador, em um ambiente político autoritário. O próprio sentido de escolha, enquanto ato político do trabalhador, estava, em si, em questão. $\mathrm{O}$ trabalhador, naquele período, não tinha direito a votar no presidente da república e seu sindicato possivelmente encontrava-se sob intervenção ou com lideranças presas ou perseguidas. Ao implantar uma política contrária ao direito à estabilidade decenal, que apenas teria efeitos caso houvesse a opção do empregado, o governo tratou de convencer as empresas a apoiarem a proposta. O papel dos empregadores foi fundamental para "instruir" seus empregados a escolher o caminho propagado como o mais seguro e, assim, garantir a política que se instalara. Neste aspecto, as discussões em torno do ato jurídico da opção poderiam levar em conta o significado mais amplo do ato de escolha, sob o risco de esvaziamento de sentidos, particularmente o jurídico, mas não o fizeram. Ainda nesta seara, é importante refletir sobre o ato individual do trabalhador de apoiar ou ir de encontro à política da ditadura, especialmente após dezembro de 1968, quando foi imposto à sociedade o Ato Institucional no 5 , o AI-5, que tornou o Estado ainda mais autoritário e violento. A propósito, entre as questões levantadas ao longo da investigação, levanta-se uma, com razoável relevância: seria possível inferir que o AI-5 afetou os ânimos das discussões jurídicas sobre o FGTS?

\section{NOTA 3: OS ENCONTROS DOS JUÍZES DA 5aㅡ REGIÃO}

Há registros documentais ${ }^{3}$ que juízes do Tribunal do Trabalho da $5^{\text {a }}$ Região, que englobava Bahia e Sergipe, promoveram encontros anuais para discussões e levantamento de sugestões sobre o Direito do Trabalho. O $1^{0}$ encontro ocorreu de 21 a 27 de outubro de 1968, o $2^{\circ}$ encontro, de 13 a 19 de outubro de 1969 e o $3^{\circ}$, de 12 a 17 de outubro de 1970. Na pauta do $1^{\circ}$ Encontro (1968), o FGTS foi o tema mais discutido pelos juízes. O Vice-Presidente do TST, e ex-Ministro do Trabalho e Previdência Social (do governo Castello Branco) Arnaldo Lopes Sussekind, procedeu a conferência de abertura, sobre Política Salarial e Dissídio Coletivo. Os juízes Antônio Carlos Oliveira, Jayme Correia, Elson Guimarães Gottschalk, Maurício Santos Pereira4, Ronald Olivar de Amorim e Souza e Vieira Lima debateram sobre aspectos do FGTS. Neste evento, várias autoridades públicas foram convidadas, além de representantes das empresas Fratelli Vita S.A., Chadler Industrial da Bahia S.A. e Petrobrás. Não foram encontrados convites a entidades sindicais de categorias profissionais. $\mathrm{O}$ coquetel de abertura ocorreu no refinado Clube Baiano de Tênis, oferecido pela Federação das Indústrias do Estado da Bahia (FIEBA). Os juízes visitaram a Petrobrás durante o Encontro e o encerramento do

\footnotetext{
${ }^{3}$ Os documentos que registram os encontros estão na biblioteca do TRT da $5^{\mathrm{a}}$ Região.

${ }^{4}$ Este juiz propôs o tema "Fundo de Garantia - empregado estável optante - desnecessidade do inquérito para apuração de falta grave". Chama a atenção que a reflexão tem como objeto a hipótese de fragilizar ainda mais o direito à estabilidade do trabalhador.
} 
evento se deu com um almoço de confraternização na Colônia de Férias do SESC, oferecido pela Federação do Comércio do Estado da Bahia.

Os $2^{\underline{0}}$ e $3^{\circ}$ Encontros repetiram esses festejos de aberturas e encerramentos nos mesmos locais e com os mesmos generosos patrocinadores, também sem convites a sindicatos ou federações de trabalhadores.

Curiosamente, no $2^{\circ}$ Encontro não houve debates sobre o FGTS, embora tenha sido aprovada decisão que serviria como orientação aos julgadores: "Na fase executória da demanda de reintegração do empregado estável, é possível ao Juiz da Execução converter a reintegração em indenização" ${ }^{5}$. Também foi deliberada a recomendação ao legislador para indicar qual o código de liberação do FGTS. Como convidados e conferencistas, o presidente do TST, ministro Télio da Costa Magalhães, o também ministro do TST, Mozart Victor Russomano, além de Calmon de Passos, professor e membro do Ministério Público no Estado da Bahia. Nos resultados deste Encontro, não houve aprovação de teses sobre política salarial ou direito coletivo do trabalho.

Entre o $1^{\mathrm{o}}$ e o $2^{\mathrm{o}}$ Encontros, no lapso de um ano, o fato político de maior relevância foi o Ato Institucional nº 5, o AI-5, publicado em 13 de dezembro de 1968. A mudança temática de um evento para o outro em tão pouco tempo talvez seja revelador dos efeitos do AI-5. Afinal, se esse ato de extrema potência despótica silenciou os movimentos de resistência à ditadura, por que não provocaria o mesmo efeito entre juízes?

O $3^{\text {o }}$ Encontro, ocorrido em 1970, não discutiu política salarial ou FGTS. Sua temática geral voltou-se ao Anteprojeto do Código Trabalhista ${ }^{6}$ e foram aprovadas sugestões para melhorá-lo.

\section{NOTA 4: O BALANÇO DO MINISTRO PASSARINHO}

Voltando ao ano do $1^{\circ}$ Encontro do Tribunal do Trabalho, importante examinar o Relatório de 1968 e o Programa de 19697, do Ministério do Trabalho e Previdência Social (MTPS), assinado pelo então ministro e militar Jarbas Passarinho, indicado por Costa e Silva. O documento, mais analítico que descritivo segundo o próprio ministro, trata do ambiente de tranquilidade nas relações de trabalho, proporcionado pelo clima político. Tal tranquilidade se justificaria pelo controle que as instituições mantiveram sobre movimentos reivindicatórios nos primeiros anos do governo militar. As instituições seriam o Ministério do Trabalho e Previdência Social e outros órgãos públicos, como a polícia. Ponderou o ministro,

\footnotetext{
${ }^{5}$ Assim como o tema proposto pelo juiz Maurício Santos Pereira em 1968, esta decisão tende a desvalorizar o instituto da estabilidade decenal.

${ }^{6}$ Esclareça-se que o anteprojeto discutido foi o encaminhado por Arnaldo Sussekind, e não aquele anterior, oriundo dos esforços de Evaristo de Moraes Filho, Mozart Victor Russomano e José Martins Catharino.

${ }^{7}$ Documento que faz parte do acervo deixado pelo professor Evaristo de Moraes Filho na Faculdade Nacional de Direito da UFRJ.
} 
por outro lado, que em 1968 houve redução da quantidade de entidades sindicais sob intervenção do MTPS. Segundo o Relatório, os números foram os seguintes: 425 entidades sob intervenção em 1964', com queda para 42 em 1967 e 18 em 1968, "quando, também eram apenas 79 as entidades dirigidas por juntas governativas". Como registro histórico, são dados relevantes. O que pode ser lido entre as linhas do Relatório, e que foi silenciado pelo ministro, é que as intervenções sindicais provocaram efeitos a longo prazo. O Sindicato dos Bancários na Bahia é exemplo emblemático: a intervenção ocorreu no dia do golpe militar e apenas em 1981 a chapa de oposição ao grupo identificado com os interventores originais conseguiu vencer as eleições sindicais. Durante esse intervalo, entre 1964 e 1981, o MTPS atuou com vigor para evitar que a organização da oposição na composição formal de chapa concorrente à direção sindical.

O documento do ministro Passarinho registra a greve geral contra a política salarial iniciada pelos bancários de Belo Horizonte e de Montes Claros, e a medida política adotada: a intervenção no Sindicato dos Bancários em Belo Horizonte. Também menciona normas ${ }^{9}$ que foram editadas pelo governo militar, que provavelmente ajudaram a forjar a mencionada "tranquilidade". Percebe-se que as medidas adotadas em 1968 possuem maior relevância nas tentativas de controle do movimento sindical.

Quadro 1. Síntese das propostas oficiais comentadas pelo ministro Jarbas Passarinho.

\begin{tabular}{|c|c|}
\hline $\begin{array}{l}\text { Decreto } \mathrm{n}^{\mathrm{o}} \text { 60.437, de } \\
\text { 06/03/1968. }\end{array}$ & $\begin{array}{l}\text { Destinado "a impedir que a vida sindical brasileira possa } \\
\text { ser conturbada por fatores externos, mediante influências } \\
\text { estranhas às reais finalidades do nosso sindicalismo". }\end{array}$ \\
\hline $\begin{array}{l}\text { Decreto-Lei } n^{\circ} \text { 368, de } \\
\text { 19/12/1968. }\end{array}$ & $\begin{array}{l}\text { Seis dias após a edição do AI-5, propôs disciplinar os efeitos } \\
\text { dos débitos salariais, "estabelecendo sanções para as } \\
\text { empresas que se atrasam sem motivo razoável no } \\
\text { pagamento de remuneração de seus empregados". }\end{array}$ \\
\hline $\begin{array}{lcc}\text { Lei } & n^{\mathrm{o}} & 5.451 \\
\text { 12/06/1968. } & \end{array}$ & $\begin{array}{l}\text { Tratou da política salarial. O MTPS designou "comissão } \\
\text { especial incumbida de elaborar uma política salarial de } \\
\text { caráter definitivo", integrada por técnicos do MTPS, } \\
\text { representantes de trabalhadores e de empresas, e de } \\
\text { representante do TST. A comissão funcionou para subsidiar } \\
\text { a elaboração da norma aprovada. }\end{array}$ \\
\hline
\end{tabular}

\footnotetext{
${ }^{8}$ Os números apresentados por Jarbas Passarinho no Relatório não conferem exatamente com os dados apresentados pelo seu antecessor, Arnaldo Sussekind (MARTINS, 1989), quando este expôs a situação das relações do trabalho em sessão da Câmara dos Deputados de 23/04/1965, em resposta ao deputado Chagas Rodrigues (PTB/PI).

${ }^{9}$ Foi mantida a ordem das normas citadas pelo ministro no Relatório. Curiosamente, a primeira delas trata de limitações às atividades sindicais, temática que inicia o Relatório, ao registrar o ambiente de tranquilidades no trabalho.
} 


\begin{tabular}{|c|c|}
\hline $\begin{array}{l}\text { Decreto no } 62.756 \text {, de } \\
\text { 22/05/1965. }\end{array}$ & Regula o controle e fiscalização das agências de emprego. \\
\hline $\begin{array}{lccc}\text { Lei } \quad n^{\text {o }} & 5.316, & \text { de } \\
\text { 14/09/1967. } & & \\
\end{array}$ & $\begin{array}{l}\text { Dispôs sobre a "integração do seguro de acidentes de } \\
\text { trabalho na previdência social". }\end{array}$ \\
\hline $\begin{array}{l}\text { Decreto } n^{\circ} \quad 365, \text { de } \\
\text { 19/12/1968. }\end{array}$ & $\begin{array}{l}\text { Desfaz "qualquer divergência" quanto à possibilidade legal } \\
\text { do MTPS utilizar recursos da Conta Emprego e Salário, } \\
\text { oriundos dos impostos sindicais "para a aquisição de } \\
\text { imóveis destinados a sedes de Delegacias" do MTPS. Uma } \\
\text { inferência possível sobre esse assunto é que haveria } \\
\text { divergência interna no governo quanto à utilização de } \\
\text { verbas arrecadas pelo Estado e o uso a ser feito. Afinal, a } \\
\text { aquisição de imóveis para sedes de delegacias regionais } \\
\text { provavelmente mobilizou valores altos. }\end{array}$ \\
\hline
\end{tabular}

Quadro elaborado pelo autor.

O Relatório menciona outros assuntos, como a facilitação da emissão de carteiras profissionais, e críticas do ministro ao funcionamento administrativo do ministério.

Além do Relatório, no mesmo documento consta um programa para o ano seguinte, 1969, com dez medidas. Destas, identificam-se aquelas com merecem maior atenção nesta pesquisa, como os dois temas:

a) aprovação de nova política salarial; b) Aprovação de plano de seguridade social; c) Reformulação do Fundo de Garantia por Tempo de Serviço; d) Revisão da Consolidação das Leis do Trabalho; e) Revisão da Lei Orgânica da Previdência Social; f) Criação de um Banco do Trabalhador; g) Reforço da inspeção do trabalho e da fiscalização da previdência social; h) Transformação e absorção do Instituto de Previdência e Assistência dos Servidores do Estado e do Serviço de Assistência e Seguro Social dos Economiários; i) Extinção ou transformação do Departamento Nacional da Previdência Social; j) Extinção ou transformação das chamadas entidades assistenciais paralelas. (MTPS, 1968)

\section{NOTA 5: RELATÓRIO DA COMISSÃO DE MEMÓRIA E VERDADE EDUARDO} COLLIER FILHO E AS ATUAÇÕES DOS PROFESSORES GOMES E CATHARINO

O ano de 1969 é marcado pelos efeitos do AI-5. As informações dos ativistas políticos perseguidos à época, em Comissões de Memória e Verdade ${ }^{10}$, e que se constitui em fato notório, é que o AI-5 gerou um recuo importante dos protestos e

\footnotetext{
${ }^{10}$ Referência à Comissão de Memória e Verdade Eduardo Collier Filho, da Faculdade de Direito da Universidade Federal da Bahia, à Comissão de Memória e Verdade do Estado da Bahia, e à Comissão Milton Santos de Memória e Verdade da Universidade Federal da Bahia.
} 
das manifestações de resistência dos opositores à ditadura, em vista do aumento da repressão. No ambiente acadêmico da Faculdade de Direito da Universidade Federal, houve um fato marcante: em 06/03/1969, o Diretor da Faculdade, professor Orlando Gomes, indeferiu os requerimentos de matrículas dos estudantes que tomaram à frente do movimento estudantil no ano anterior e que lideraram manifestações e greves estudantis na instituição ${ }^{11}$.

A maior parte desses estudantes manteve os estudos em Direito, seja pela transferência à Universidade Católica de Salvador (UCSal), dirigida pelo professor Manoel Ribeiro, e pertencente à estrutura da Igreja Católica, ou para a Faculdade Cândido Mendes, no Rio de Janeiro, cujo responsável mantinha forte ligação com a Igreja Católica. Não é de se descartar a possibilidade de interferência de ativistas católicos para que os estudantes conseguissem concluir seus cursos nessas duas instituições. Outra parte dos estudantes conseguiu manter o curso na Faculdade de Direito da Universidade Federal, em razão de mandado de segurança impetrado para assegurar-lhes o direito. Outros estudantes não mais voltaram a estudar, como Eduardo Collier Filho, considerado até hoje desaparecido político ${ }^{12}$.

O indeferimento do pedido de matrícula não foi ato administrativo e de força dos militares, mas conduta do Diretor da Faculdade que, ao ser questionado, se referiu a "ordens superiores", sem indicar à sociedade e ao alunado impedido de continuar a estudar na instituição, as origens e quais seriam essas ordens. Infere-se, a exemplo do ato do Diretor, que a repressão, logo após o AI-5, não ficou a cargo exclusivo dos órgãos próprios de repressão. No caso concreto da Faculdade de Direito da Universidade Federal da Bahia - como talvez tenha ocorrido em outros tantos centros estudantis -, houve uma mudança radical de 1968 para 1969, isto é, de um ano cujas manifestações estudantis praticamente inviabilizaram as atividades regulares de ensino na Faculdade, dado o impasse em negociações entre o movimento estudantil e a direção da instituição ${ }^{13}$, para o ano seguinte, em que as lideranças mantiveram-se cautelosamente silenciosas e em que era perigosíssimo frequentar reuniões estudantis, pela possibilidade de haver repressão. Neste passo, a conduta do diretor em março de 1969 ampliou o medo, pois sinalizou com a

11 O Relatório Parcial da Comissão de Memória e Verdade Eduardo Collier Filho, da Faculdade de Direito da Universidade Federal da Bahia, tratou desses eventos.

${ }^{12}$ Não há confirmação sobre a localização do corpo de Collier Filho ou onde tenha sido morto, pois não se questiona o seu assassinato pelas forças da ditadura. "Em seu relatório final, a CNV apresentou uma lista com treze nomes de militantes que poderiam ter passado pela Casa da Morte a partir de fevereiro de 1974" (GÓMEZ, 218, pág. 487), e um deles teria sido Eduardo Collier Filho.

${ }^{13} \mathrm{O}$ diretor decidiu pelo fechamento da Faculdade por volta do segundo semestre de 1968, em função do clima acirrado provocado pelas manifestações dos estudantes. Dentre a documentação da época, destaca-se carta do professor Auto de Castro à Congregação da Faculdade, com críticas ácidas à atuação do Diretor. Os documentos compõem o acervo do Memorial da Faculdade de Direito da UFBA e serviram para a produção do Relatório da Comissão de Memória e Verdade Eduardo Collier Filho. 
concretude de prejuízos reais aos estudantes sem que houvesse atos das forças policiais.

A Faculdade de Direito era ambiente de prestígio na comunidade dos juristas baianos e o que ocorria lá repercutia no extramuros. Os Encontros do Tribunal do Trabalho de 1968, 1969 e 1970, por exemplo, utilizaram o novo e espaçoso prédio da Faculdade, inaugurado em 1961.

O professor José Martins Catharino teve atuação destacada em 1968 como membro da comissão de processo administrativo aprovado pela Congregação da Faculdade de Direito, com o objetivo de avaliar a conduta dos três alunos denunciados pelo movimento estudantil como agitadores favoráveis à ditadura e agressores de estudantes em manifestações. A comissão foi aprovada pela Congregação da Faculdade em 16/08/1968 a partir de proposta formulada pelo próprio José Martins Catharino (que a compôs junto com mais dois professores: José Joaquim Calmon de Passos e João de Oliveira), com os votos contrários da representação estudantil. O processo administrativo pareceu ser uma proposta intermediária entre a posição do Centro Acadêmico Ruy Barbosa (CARB) ${ }^{14}$, que desejava a exclusão dos três alunos da Faculdade, e a do diretor, que negava o pedido do movimento estudantil.

O Serviço Nacional de Informações (SNI) acompanhou os trabalhos da comissão, como demonstra o documento denominado "Informação no 79/NASV SNI/68", de 08/10/1968, preocupado com a hipótese de "expulsão dos alunos democratas" 15 e o risco dessa atitude se alastrar para outras Faculdades e atingir estudantes "que ajudam as Forças Armadas". A leitura do SNI sobre a comissão e o professor José Martins Catharino era a seguinte:

3. Comenta-se abertamente que os três Professores designados são da linha esquerdista, conhecidos da comunidade bahiana, pelas idéas e teses que professam. O Prof. JOSÉ MARTINS CATARINO, foi Presidente do Partido Socialista Brasileiro, Secção Bahia, elemento do proa para todo o movimento auxiliar comunizante. $\mathrm{O}$ Prof CALMON DOS PASSOS segue a mesma linha ideológica.

O resultado da comissão foi concluído e apreciado na sessão da Congregação do dia 14/11/1968. Contra os votos dos estudantes e de alguns docentes, dentre os

\footnotetext{
${ }^{14}$ A posição da entidade estudantil encaminhada à Congregação não deixa dúvidas: “Declara que a Assembleia Geral não examinou o problema jurídico e sim o político. Entenderam os estudantes não ser possível a presença na Escola, na sala de aula e nas dependências do próprio da Universidade, de um aluno incumbido de obter e encaminhar informações de colegas outros às autoridades policiais. Os estudantes - continua o presidente do Carb - resolveram, em caráter irrevogável, não permitir, mais, as presenças dos três estudantes. Esta decisão é do corpo discente da Escola."

15 "Democratas", no contexto do documento, referia-se a apoiadores da ditadura.
} 
quais José Martins Catharino, a Congregação posicionou-se contra a expulsão dos três alunos. Um mês depois, foi editado o AI-5.

Dos registros das atas da Congregação dos anos de 1968 a 1970, verifica-se que em 1968 houve oito reuniões, em 1969, seis e em 1970, duas. Houve queda também do calor das discussões após 1968. Rosalindo Souza, principal liderança do CARB, não teve sua matrícula deferida pelo diretor da Faculdade em março de 1969.

\section{NOTA 6: DOCUMENTOS DOS ÓRGÃOS DE REPRESSÃO DA DITADURA} SOBRE OS JURISTAS ORLANDO GOMES E JOSÉ MARTINS CATHARINO

Com a criação da Comissão Nacional da Verdade, o Arquivo Nacional disponibilizou à sociedade parte do acervo documental recebido por órgãos públicos responsáveis pela repressão política no país ao longo da ditadura civilmilitar. Dois conjuntos de documentos coletados desse acervo servem para compreender, com mais precisão, o papel desempenhado pelos intelectuais Orlando Gomes e José Martins Catharino.

Inicialmente sobre Orlando Gomes. O documento produzido pela $6^{\mathrm{a}}$ Região Militar do Exército, denominado "Informação no 393-E 2", de 22/05/1976, referente a investigação feita pela agência de Salvador do SNI, acerca de "pessoas cogitadas para Diretor e Vice-Diretor da Faculdade de Direito da UFBA", registrou recortes e anotações de reportagens em jornais baianos com posicionamentos de Orlando Gomes.

Em um primeiro recorte, há a fala do jurista na Federação do Comércio sobre o FGTS. Segundo a reportagem do Jornal da Bahia de 13/01/1967, Gomes era favorável à proposta. No trecho destacado pelos militares, há referência à "tese marxista da mais valia". É provável que este trecho tenha sido escolhido em razão da menção feita pelo jurista de expressão inadequada aos olhos anticomunistas dos censores. Mas também é possível identificar um posicionamento mais refinado de apoio ao FGTS, equidistante da defesa feita pelo próprio governo. É o que sugere o teor da reportagem do jornal A Tarde, daquele mesmo dia. Orlando Gomes conclui que o Fundo de Garantia permitiria uma restituição ao trabalhador do valor apropriado pelo patrão ao longo do contrato, caracterizado como mais-valia por Marx. Neste sentido, a teoria do filósofo e economista alemão estaria confirmada no cenário das relações trabalhistas em meio às alterações impostas pela ditadura.

Em outro recorte constante do documento, a reportagem do Jornal da Bahia de 27/07/1967 revela a decepção do jurista com a elite nacional, de "mentalidade provinciana, preconceituosa, rústica, primária", em descompasso à "prosperidade material do país". De certa forma, confirmava ali uma postura crítica de Gomes, pouco entusiasta de um pensamento, digamos, subdesenvolvido. Lembre-se, próximo a esta linha, o estudo de José Eduardo Faria, em artigo que considerou Orlando Gomes, San Tiago Dantas e Raimundo Faoro, exemplos de "juristas fora da curva", pela visão avançada que tinham em comparação aos positivistas das suas épocas. Pondere-se que o Gomes estudado por Faria fora aquele intelectual 
em época anterior à ditadura. A reportagem cobriu um banquete em homenagem a Orlando Gomes, ocorrido no Hotel da Bahia, que reuniu políticos, membros do judiciário, advogados, acadêmicos e dirigentes das federações da indústria, do comércio e da agricultura, segundo informou o jornal A Tarde, de 27/07/1967, que transcreveu o discurso proferido pelo jurista.

Na edição do jornal A Tarde, de 18/10/1967, Orlando Gomes publicou o artigo "Torturas dos leguleios nativos", em que manifestou angústia em relação à desarticulação do ordenamento jurídico brasileiro e a falta de boa técnica legislativa, causada pelo que chamou de "três anos de diarreia legislativa". Alfinetou a atuação do governo naqueles tempos, relacionada à produção de normas, provocando "caos no fôro e na academia. A confusão não vem apenas do número. Vem, principalmente, da má qualidade". A crítica do jurista, concentrada em questões do Direito Civil, chamou a atenção das antenas da ditadura.

Também no jornal A Tarde, em edição do dia 15/05/1968, Orlando Gomes criticou a política salarial oficial pautada no arrocho da renda dos trabalhadores, seja pelo "aspecto humano do problema", seja pela desconfiança dessa política enquanto fomentadora do desenvolvimento, por afetar negativamente o consumo.

Enfim, sua postura revelava autonomia crítica e intelectual em relação a condutas da técnica jurídica do governo. Considerava a necessidade de equilíbrio diante da conjuntura, embora não tenha sustentado uma crítica política contundente ao estado de coisas autoritário daqueles momentos.

Sobre José Martins Catharino. O conjunto de documentos denominado “Informação n⿳o 0033/740/ASV/80", do SNI, de 07/02/1980, referente aos "Antecedentes" de Catharino, registrou uma série de anotações, além de fatos e eventos em que o intelectual estaria envolvido, identificando-o como opositor à ditadura:

- Em Abr 68, assinou manifesto dos intelectuais, jornalistas, professores e artistas, protestando contra as violências policiais.

- Foi destinatário ${ }^{16}$ de carta procedente do INSTITUTO LATINOAMERICANO DE DERECHO DEL TRABAYO Y DE LA SEGURIDAD SOCIAL-ARGENTINA, na qual lhe é solicitada a remessa da importância de dez dólares, com a finalidade de fazer face às despesas que decorreriam com cunhagem de uma medalha e confecção de diploma, os quais identificariam os membros desse Instituto.

${ }_{16}$ Pela leitura do documento e sua cronologia, o fato teria ocorrido em 1973. A articulação de Catharino com juristas argentinos tem relevância nesta pesquisa e se trata de assunto a ser explorado com mais cuidado, em vista da repressão que se abateu a juristas trabalhistas após o golpe de Estado na Argentina, em 24/03/1976, a exemplo do assassinato de Norberto Oscar Centeno, em 1977. 
- Segundo a $6^{0} \mathrm{RM}^{17}$, o nominado manifestou-se em algumas oportunidades, com declarações à imprensa e conferências, contrário aos atos posteriores a Revolução: acordo MEC/USA1D, organização judiciária e modificações introduzidas na CLT.

Nesta mesma documentação, consta o “Informe no 0090/80-SI/SR/DPF/BA", de 24/01/1980, produzido pela Polícia Federal, também com notas sobre a atuação de Catharino. Dentre elas, consta que, "na primeira reunião do Conselho Universitário do ano de 1969", ele teria "apresentado uma moção de solidariedade ao prof. MARCELO FERREIRA DUARTE GUIMARÃES, que teve seu mandato de Deputado Estadual cassado com base no AI-5." Há também a "Informação nº 010; E2, da 6 a Região Militar do Exército, de 25/01/1980, com os mesmos dados e pequenas variações. No “Informe no 0001/740/ASV/80", de 11/02/1980, da Agência de Salvador do SNI, constam que:

2. Sempre que é convidado participa de seminários, conferências e palestras patrocinados por estudantes. Nessas ocasiões faz críticas contudentes e sarcásticas ao Governo, principalmente no que diz respeito a política do Setor Trabalhista.

$(\ldots)$

4. Milita na Justiça do Trabalho, desde a sua fundação.

5. É jurista equilibrado, educado e bastante conhecido nacionalmente, inclusive com livros publicados.

6. Defende a liberdade de escolha, posicionando- se contra o sistema institucional vigente, por considerá-lo inadequado.

A ditadura compôs o levantamento de dados biográficos de Catharino, assim como de tantos outros cidadãos que suspeitava opositores ao regime. A ficha $\mathrm{n}^{\mathrm{o}}$ 42248/80 consta que o jurista estava cogitado para ocupar o cargo de diretor da Faculdade de Direito. A apreciação do formulário padrão continha seis questões, seguidas de opções que foram marcadas pelo avaliador, abaixo reproduzidas, sublinhando as opções marcadas para José Martins Catharino:

1. Sobre sua posição ideológica, seria esquerdista (as outras opções eram: democrata, comunista e sem posição definida).

2. Sobre sua atitude em relação à "Revolução de 31 Mar 64", teria sido contrário (as outras opções eram: integrado, adesista e contrarevolucionário).

3. Sobre atividades subversivas, seria simpatizante (a outra opção era atuante).

4. Sobre probidade administrativa, não havia registros (as demais opções eram: registros positivos e registros negativos).

17 Pela leitura do documento e sua cronologia, o fato teria ocorrido em 1974. 
5. Sobre a eficiência funcional ou profissional, anotaram "há registros positivos". As opções outras eram: há registros negativos e não há registros.

6. E, enfim, sobre sua conduta civil, não havia registros. As outras opções eram: registros positivos e registros negativos.

No final do documento, a "apreciação final" oferecia as seguintes alternativas: "não há restrições; os registros existentes não contra-indicam o aproveitamento; não existem elementos de convicção que contra-indiquem o aproveitamento; não há registros; não deve ser aproveitado". Segundo o avaliador, o jurista José Martins Catharino não deveria ser aproveitado para o cargo de diretor da Faculdade de Direito.

Inevitável a comparação entre os professores Orlando Gomes e José Martins Catharino neste quesito, em vista do primeiro ter ocupado a direção da Faculdade de Direito, inclusive no período posterior ao AI-5.

\section{NOTA 7: RELATÓRIO DE ATIVIDADES DA CONTEC}

O movimento sindical ocupou-se de debater sobre os desafios que os trabalhadores enfrentavam com a ruptura democrática em 1964 e o Estado de exceção. É o que demonstra o Relatório das Atividades da Confederação Nacional dos Trabalhadores nas Empresas de Crédito (CONTEC) ${ }^{18}$, relativo ao ano de 1966, apresentado pelo Conselho Diretor da entidade à Assembléia Geral em 16/03/1967. Destaca-se, no documento, a discussão em torno do direito à estabilidade e o FGTS. O Relatório formulou críticas a propostas do governo militar, com menção ao Programa de Ação Econômica do Governo, de novembro de 1964, e à monografia "Aperfeiçoamento da Estabilidade", do Ministério Extraordinário para o Planejamento e Coordenação Econômica, de julho de 1966. Também faz parte do Relatório trechos de Parecer que a CONTEC solicitou ao jurista Mozart Victor Russomano em defesa do direito da estabilidade. Outros juristas também são citados neste mesmo sentido, assim como a entrevista que Evaristo de Moraes Filho concedeu ao jornal Correio da Manhã, em 03/04/1966.

\section{NOTA 8: ELEIÇÕES SINDICAIS ACOMPANHADAS PELO GOVERNO MILITAR. O CASO DO SINDICATO DOS BANCÁRIOS NA BAHIA}

As eleições sindicais deveriam ser organizadas pelos trabalhadores interessados, no entanto se tornaram um exemplo da ingerência oficial e da negação à autonomia sindical. Caso paradigmático é o do Sindicato dos Bancários da Bahia. Dois grupos de documentação foram analisados, e percebe-se o quanto a ditadura monitorou as chapas de oposição, em uma triagem política de quem poderia compor, ou não, a direção do Sindicato, após a intervenção oficial sofrida em

\footnotetext{
${ }^{18}$ Documento que faz parte do acervo deixado pelo jurista e professor Evaristo de Moraes Filho na Faculdade Nacional de Direito da UFRJ.
} 
01/04/1964, quando foi compulsoriamente afastado o seu presidente, Raimundo Reis $^{19}$.

Para as eleições do Sindicato dos Bancários de 1978, o Delegado Regional do Trabalho na Bahia, Ivanilson Soares Trindade, encaminhou Ofício (OF.DRT.DAS.SOS.№131), em 28/04/1978, ao "Ilmo. Sr. Coronel do S.N.I." (Coronel Pedro Correia Bruni, Chefe do SNI), solicitando informação sobre "qualquer registro desabonador que desaconselhe o aproveitamento de algum dos nomes constantes das relações anexa de candidatos às eleições (...) marcadas para os dias 26, 27, 28, 29 e 30 de junho de 1978."

Resposta parcial do Chefe da ASV/SNI ao Delegado Regional do Trabalho (Ofício no 0094740/ASV/78, de 19/05/1978), solicita informações sobre "incidente ocorrido durante as eleições para o Sindicato dos Empregados em Estabelecimentos Bancários do Estado da Bahia, realizadas em Jul 75, envolvendo o bancário PEDRO BARBOZA DE OLIVEIRA NETO."

No mesmo dia que recebeu a solicitação, o Delegado Regional do Trabalho retornou ao Chefe da ASV/SNI, informando-o (OF/GD/ASI/№ 27/78, de 19/05/1978 (portanto, no mesmo dia que recebeu a solicitação) "que a sindicância relativa às atividades desenvolvidas pelo bancário PEDRO OLIVEIRA NETO, durante as eleições de 1975, foi feita pela diretoria do Sindicato dos Bancários, à época dos fatos, não tendo, entretanto, a referida entidade comunicado a esta DRT, seu resultado, pelo que não dispomos de elementos para atender à solicitação dessa AI."

O Chefe do SNI solicitou ao Doutor Juiz Auditor da 6 $6^{\mathrm{a}}$ CJM (Ofício no 0093740/ASV/78, de 19/05/1978) informações, "com a possível brevidade", sobre IPM em que Carlos Azevedo de Araújo teria sido indiciado "no interior da Bahia (...) após o movimento revolucionário de 1964, sendo incurso no Art. $2^{\circ}$, alínea III, da Lei 1802/53, de 05 Jan."

Em documento da ASV/SNI, de 20/06/1978, denominado "Encaminhamento n⿳ 0020/740/ASV/78", que tem como Referência o “Ofício no 046/74/AC/77, de 21 Dez" ${ }^{20}$, há informações sobre Paulo Morais Silva, Carlos Azevedo de Araújo, Pedro Barboza de Oliveira Neto e Djalma Medrado Passos, e como anexos, o Prontuário nº 2.289, o "Levantamento de Dados Bibliográficos no 0010/740/ASV/78" e a "Ficha Sintética de Apreciação sobre o Levantamento de Dados Bibliográficos" ${ }^{21}$, todos sobre Paulo Morais Silva.

Através do Ofício no 0122740/ASV/78, de 22/06/1978, o Chefe da ASV/SNI respondeu ao Delegado Regional do Trabalho, com informações sobre os candidatos às eleições do Sindicato dos Bancários cujos nomes constavam dos seus arquivos, agrupando-os em quatro diferentes itens, a depender da situação: a.

\footnotetext{
${ }^{19}$ A pesquisa tem como uma das fontes a entrevista concedida pelo sr. Raimundo Reis.

${ }^{20}$ AC significa Agência Central do SNI.

${ }^{21}$ Mesmo tipo de formulário padrão que foi utilizado para avaliar o aproveitamento de José Martins Catharino.
} 
"aguarda-se conclusão de processamento"; b. "não existem elementos de convicção que contra-indiquem o aproveitamento"; c. "os registros existentes não contraindicam o aproveitamento"; d. "não há restrições quanto ao aproveitamento".

Em 11/07/1978, consta do Telex aparentemente enviado da Agência Central do SNI à ASV/SNI, a "Mensagem no 12086/74/AC/78", o qual informa que "a título de cooperação que existem restrições quanto ao aproveitamento de Paulo Morais Silva, para eleições no Sindicato dos Empregados em Estabelecimentos Bancários da Bahia".

O teor do Telex fundamentou o Ofício nº 0142740/ASV/78, de 12/07/1978, do Chefe ASV/SNI ao Delegado Regional do Trabalho, que complementou o Ofício n ${ }^{\circ}$ 0122740/ASV/78, de 22/06/1978, para informar que havia restrições a Paulo Morais Silva quanto ao aproveitamento.

Resposta do Dr. Arnaldo Silva Ferreira Lima, Auditor da Auditoria da $6^{\mathbf{a}}$ Circunscrição Judiciária Militar (Ofício no 706, de 31/07/1978), informou que Carlos Azevedo de Araújo "não respondeu e nem responde a qualquer processo nesta Auditoria". Deste documento, consta ainda passagem curiosa, em que o Auditor demonstra que as solicitações sobre dados eram respondidas rapidamente, mas com falhas, como indica o nome equivocado do ativista e a justificativa para a demora da busca.

Informo que ao tempo dos fatos esta Auditoria não possuía livros de registros de indiciados, motivo pelo qual este Juízo não pode dar os dados de qualificação de CARLOS REZENDE DE ARAUJO.

Esclareço que a demora no responder aos oficies acima evidenciados foi pelas diversas buscas dadas nos livros deste Juízo Militar.

A pedido da ASV/SNI, houve levantamento por parte da $6^{\mathbf{a}}$ Região Militar ( $2^{\mathrm{a}}$ Seção) do Ministério do Exército, registrado como "Informação nº 305/E2", de 30/05/1978, sobre Carlos de Azevedo Araújo e Djalma Medrado Passos.

Em um outro documento, há notícias sobre assunto similar, focado em um dos membros da chapa de oposição, conforme a "Informação no 1298/25/SNI/ASV/74", da Agência de Salvador do SNI. Conta que o bancário Joselício Oliveira

em 1968 trabalhava no Banco do Trabalho, consta como informe / ser: fichado como comunista, agitador e ex-membro do CPOSE, também faz parte da firma CACON; em 1968 concorreu às eleições do Sindicato dos Bancários tendo a sua candidatura vetada pelo Ministro do Trabalho, a qual era encabeçada pelo Sr. GEORGES ANTONIO GUIMARÃES SÁ. É tido como elemento distribuidor de panfletos no meio bancário. 
O acompanhamento de eleições sindicais era importante para o governo militar, como se infere da "Informação no 3019/DSI/MIC/79", do Ministério da Indústria e do Comércio, Divisão de Segurança e Informações, datado de 16/11/1979, que tem como "Assunto: DIN - 4.2.5 - Valorização do Sindicato como Organização Social", e "Referência: Plano Setorial de Informações". Este registro encerra com uma análise de conjuntura que sugere que o clima de tranquilidade mencionado por Jarbas Passarinho em 1968 já não existia:

\section{4 - CONCLUSÃO}

No momento em que o Pais vive um clima de realização de eleições nos diversos Sindicatos, bem como de inúmeras reivindicações nos vários setores de atividade, com greves, passeatas etc, há um contínuo aproveitamento desses movimentos reivindicatórios por parte de parlamentares e entidades oposicionistas ao regime.

Conhecidos agitadores apresentam-se junto aos líderes de movimentos, apoiando-os, e infiltrando-se entre os trabalhadores para insuflar e fazer proselitismo marxista.

Esta Divisão tem acompanhado com interesse a atuação dos Sindicatos na área do MIC, visando, principalmente, a identificação de líderes e as próximas eleições nessas entidades.

Nesses movimentos que normalmente provocam dissídios e declaração, pelas autoridades, da ilegalidade da greve, sempre estão presentes as reivindicações salariais, estas muito acima dos índices previstos na Politica Salarial do Governo. Ao lado dessas reivindicações ponteiam, também, líderes que, dos mais variados setores da sociedade brasileira, e infiltrados nos Sindicatos, ou dizendo-se seus defensores, desvirtuam as finalidades das organizações sindicais.

Em suma, o aparato repressor moveu-se agilmente para identificar impedimentos às chapas de oposição à direção do sindicato. Nos documentos examinados, que circularam entre instituições oficiais como passos silenciosos entre as sombras, em 1968 e 1978 as chapas tiveram dificuldades para disputar as eleições, o que facilitou a manutenção de dirigentes de confiança da ditadura nas direções dos sindicatos.

\section{NOTA 9: A MONTAGEM DO CENÁRIO}

Isto posto, chega-se na questão: a análise articulada dos documentos acima permitiria a montagem de um cenário apropriado para um exame da cultura jurídica no período da ditadura?

É possível identificar que juízes do trabalho da Bahia e de Sergipe, em seus encontros anuais de 1968 a 1970, se conduziram de maneira compatível com as preocupações expostas pelo ministro Jarbas Passarinho, quanto a um suposto clima 
de tranquilidade que se instalava no país. As perseguições a lideranças sindicais não estiveram presentes nos debates daqueles encontros, e as entidades sindicais e personalidades não judiciais convidadas ou promotoras dos eventos eram de representações patronais. A conduta do judiciário em relação ao FGTS mostrou-se limitada a temas técnicos sobre a liberação e uso pelo trabalhador ou o eventual manejo da estabilidade, sem que houvesse críticas à novidade proposta pelo governo militar.

Já o ambiente acadêmico da Faculdade de Direito até 1968 espelhou os confrontos que se revelavam na sociedade. Nesse ambiente, os dois juristas escolhidos não foram tímidos em suas posições quando tiveram oportunidades de expressá-las. Orlando Gomes, como diretor, se opôs ao movimento estudantil, e José Martins Catharino tentou viabilizar meios institucionais de canalizar o protesto dos estudantes (pela via do processo administrativo), mesmo sem o apoio das suas representações. Em 1969, após o AI-5, Gomes vetou a permanência das lideranças estudantis na Faculdade, já Catharino manifestou-se publicamente contra a cassação de um professor pelo autoritário Ato Institucional de dezembro de 1968. Ambos os juristas eram respeitados pelos militares por seus respectivos percursos enquanto professores e intelectuais. Embora houvesse diferenças entre os dois aos olhos da ditadura, afinal Gomes foi diretor da Faculdade e Catharino não poderia ser aproveitado nesse cargo, Orlando Gomes teceu críticas ao atraso das elites no país e à condução das propostas de mudanças nas legislações trabalhistas.

Em comum, juízes e ambiente acadêmico sofreram os efeitos do AI-5, percebidos pelo medo e cuidado nos debates. E não era à toa, pois se até mesmo as discussões em torno de novas regras propostas pela ditadura eram controladas, a atividade política da sociedade foi duramente fiscalizada e reprimida, como demonstram o documento da CONTEC e as eleições sindicais dos bancários baianos.

\section{NOTA 10: AS POSIÇÕES DOS JURISTAS SOBRE O FGTS E O DIREITO À ESTABILIDADE}

Na 3 ${ }^{a}$ edição da obra Curso de Direito do Trabalho, de 1968, Orlando Gomes e Elson Gottschalk apresentam uma Nota específica, em que elencam as novas normas trabalhistas do então recente regime autoritário: desde a lei de 1964, que regulamentou o direito de greve à lei que tratou do FGTS, e pontuam duas críticas: uma, quanto às "transformações do direito positivo do trabalho, atestando o propósito do Govêrno de renová-lo pelo método condenável da reforma fragmentária, que está a desconjuntar o sistema traçado na Consolidação"; e outra em relação à necessidade da garantia da autonomia coletiva, "contra a qual de conservam prevenções nos países subdesenvolvidos". Gomes e Gottschalk defendiam a função do Direito Coletivo do Trabalho "de singular relêvo onde se 
reconhecem aos trabalhadores a possibilidade da autotutela dos seus interesses profissionais".

O tópico $\mathrm{n}^{\mathrm{o}} 175$ da obra, específico sobre o Fundo de Garantia de Tempo de Serviço, conta, na parte final, com o que os autores chamam de crítica. Ao abordar a possibilidade de escolha do empregado pelo FGTS, o fazem como direito e manifestação de liberdade do trabalhador, mas não tocam na condição em si da escolha e quedam-se indiferentes em relação ao contexto político, absolutamente contrário à liberdade do empregado, que é o pressuposto que os autores veem no ato da opção. A autonomia da vontade individual do empregado revela-se, aos autores, como algo formal, deslocado da realidade, pois esta sequer é trazida às críticas. Dois temas são levantados também: a fragilização do direito à estabilidade, que poderia ser transacionada pelo direito à indenização, e o FGTS como aumento do ônus patronal.

Em Temas de Direito do Trabalho (1ª edição), José Martins Catharino (1971, p. 163) comenta o direito coletivo do trabalho no Brasil: "Em regime de 'liberdade protegida' - o nosso, o Estado reforça a capacidade de ação dos sindicatos, mas não o faz graciosamente (...). Dá-lhes algumas capacidades normativa e tributária, massa coíbe seus ímpetos revolucionários ou reformistas." Vale o registro também do seu posicionamento sobre a liberdade sindical, influenciado por Georges Spyropoulos, especificamente sobre o que se constituiria a "liberdade sindical das relações dos sindicatos com o Estado", comenta:

a) a independência dos sindicatos frente ao Estado: liberdade de constituição, liberdade de funcionamento (interno e externo) e liberdade de dissolução; b) o conflito entre a autoridade do Estado e a ação sindical, no seu duplo aspecto divergente: o enfraquecimento da autoridade estatal, que produz, por consequência, a extensão e a intensidade da ação sindical, e , em sentido contrário, o robustecimento da primeira e a corolária redução da segunda; c) a integração dos sindicatos no Estado, mediante subordinação (Itália fascista, Portugal e Espanha, e a França, no regime da 'Charte du Travail', de 1941), ou mediante interdependência (nas democracias marxistas. (CATHARINO, 1971, p.171)

Catharino (1971, p. 119) aprofunda-se nos estudos sobre o direito à estabilidade. Ele considera que os direitos trabalhistas devem acompanhar a dinâmica do desenvolvimento social. Sobre a estabilidade, diz que "o instituto revela um movimento dialético entre liberdade (do empregador) e segurança (do empregado), sendo uma fórmula de coordenação entre ambas".

\section{CONCLUSÃO}


O silêncio dos juízes do trabalho quanto às perseguições contra sindicalistas e intervenções em sindicatos, naqueles eventos de 1968 a 1970, e a convocação de participação apenas de entidades sindicais patronais, revelam um posicionamento político de evitar debates, confrontos e constrangimentos aos militares e seus representantes. Com isso, o judiciário também assumiu posição. A partir da experiência argentina, o jurista Raúl Zaffaroni, ex-membro da Suprema Corte da Nação, sintetizou com habilidade e contundência essa posição dos tribunais:

O modelo inquisitorial, em que todas as funções processuais se concentram no 'tribunal', porque este não é imparcial se não que sempre para 'o bem', faz que estes deixem de ser juízes e passem a ser polícias. Em um sentido moderno, os inquisidores não eram juízes, como tampouco eram os integrantes dos tribunais políticos 'especiais', como el Volksgericht nazi. Os tribunais dos estados absolutos sempre são tribunais policiais, órgãos administrativos por sua dependência e parcialidade. Um estado de polícia sociologicamente falando - é um estado em que as agências policiais operam sem limitações, seja a Gestapo, a KGB ou o serviço de inteligência de qualquer ditadura. No melhor dos casos, estes 'tribunais' seriam meros controles internos da administração. Não eram propriamente juízes os que exerciam a magistratura nas ditaduras latino-americanas, anda que os regímenes constitucionais se viram forçados a reconhecer o valor de suas

Como parte dos efeitos do AI-5, três ministros do STF (Hermes Lima, Evandro Lins e Silva e Victor Nunes Leal) foram afastados (RECONDO, 2018), além de outras perseguições havidas contra magistrados pais afora. Daí em diante, o silêncio instalado em 1964 se ampliou e a cultura jurídica, enquanto ambiente discursivo de abstração intelectual que afeta e é afetado pela dinâmica da sociedade, ficou profundamente marcado pelo medo, que imobilizou seus sujeitos. A escassa produção crítica às posturas despóticas por parte dos tribunais e dos juízes, passa a ter grande dificuldade para se tornar referência para a sociedade. Estudos sobre a produção jurídica desse período deixam de levar em conta os efeitos do contexto autoritário e passam, então, a vigorar na formação dos bacharéis e nas fontes do direito enquanto doutrinas e jurisprudências.

Destas notas ainda provisórias, é possível concluir que a reflexão jurídica e a atuação judiciária sentiram a força da repressão política. A ditadura praticou

${ }^{22}$ Livre tradução. 
terrorismo de Estado ${ }^{23}$ que não foi baseado apenas em atos de força dos próprios agentes do Estado, mas de colaborares, seja pela identificação política com as propostas defendidas pela ditadura, seja pela imobilização imposta pelo medo. $\mathrm{O}$ ambiente da Faculdade de Direito após o AI-5 viu poucos arroubos de ousadia dos juristas, assim como revelaram as discussões dos encontros dos juízes, em um outro ambiente. Nesse contexto, parece ter ficado prejudicado e limitado o debate em torno da novidade do direito do trabalho que formalmente dependia da vontade do empregado, o FGTS, e que desestruturou um dispositivo que ainda dialogava com a realidade econômica do país em busca de pacificação (o direito à estabilidade decenal, previsto no art. 492 da CLT).

O espaço público de debates, que poderia influenciar e contribuir com juízes e juristas, também foi anulado, em vista das intervenções em sindicatos e das perseguições contra sindicalistas. Poucas vozes se sustentaram em debates teóricos como, no caso da Bahia, Orlando Gomes e José Martins Catharino. Por outro lado, as posturas dos juristas enquanto acadêmicos devem ser observadas e analisadas, e as avaliações feitas pela ditadura quanto ao aproveitamento desses dois juristas para a direção da Faculdade são reveladoras: enquanto Orlando Gomes dirigiu a Faculdade, e nesse papel excluiu do curso jovens ativistas contrários à ditadura, Catharino era preterido para o cargo de diretor, o qual nem sequer se candidatou.

Enfim, a proposta dessas Notas é estabelecer teias de articulações entre fatos e processos, que permitam compreender a cultura jurídica, a postura dos juízes e o ambiente de discussões, ou a falta delas.

\section{REFERÊNCIAS}

BRASIL, Ministério do Trabalho e da Previdência Social (MTPS). Relatório de 1968 e Programa de 1969. Brasília, 1968.

CATHARINO, José Martins. Temas de Direito do Trabalho. 1 ed. Rio de Janeiro Guanabara: Edições Trabalhistas S/A, 1971.

GOMES, Orlando; GOTTSCHALK, Elson. Curso de Direito do Trabalho. 3 ed. Forense: Rio de Janeiro/São Paulo, 1968.

GÓMEZ, José María (Coord.). Lugares de memória; ditadura militar e resistências no estado do Rio de Janeiro. Rio de Janeiro: Ed. PUC Rio, 2018.

\footnotetext{
${ }^{23}$ Expressão pouco utilizada na literatura brasileira, mas recorrente nas análises dos argentinos sobre a ditadura, conforme se vê em Duhalde (2014).
} 
DUHALDE, Eduardo Luis. El Estado Terrorista argentino. Buenos Aires:

Colihue, 2014.

FERRANTE, Vera Lúcia B. Ferrante. FGTS: ideologia e repressão. São Paulo: Editora Ática, 1978.

RECONDO, Felipe. Tanques e togas: o STF e a ditadura militar. São Paulo: Companhia das Letras, 2018.

REGINATO, Andréa Depiere de A. Uma introdução à pesquisa documental. In: MACHADO, Maíra Rocha (Org.). Pesquisar empiricamente o direito. São Paulo: Rede de Estudos Empíricos em Direito, 2017.

MARTINS, Heloisa Helena Teixeira de Souza. O Estado e a Burocratização do Sindicato no Brasil. São Paulo: Editora Hucitec, 1989.

ZAFFARONI, Eugenio Raúl. Crímenes de massa. Buenos Aires: Ediciones Madres de Plaza de Maio, 2012. 